\title{
El caballero del verde gabán (1)
}

\section{The gentleman in the green greatcoat}

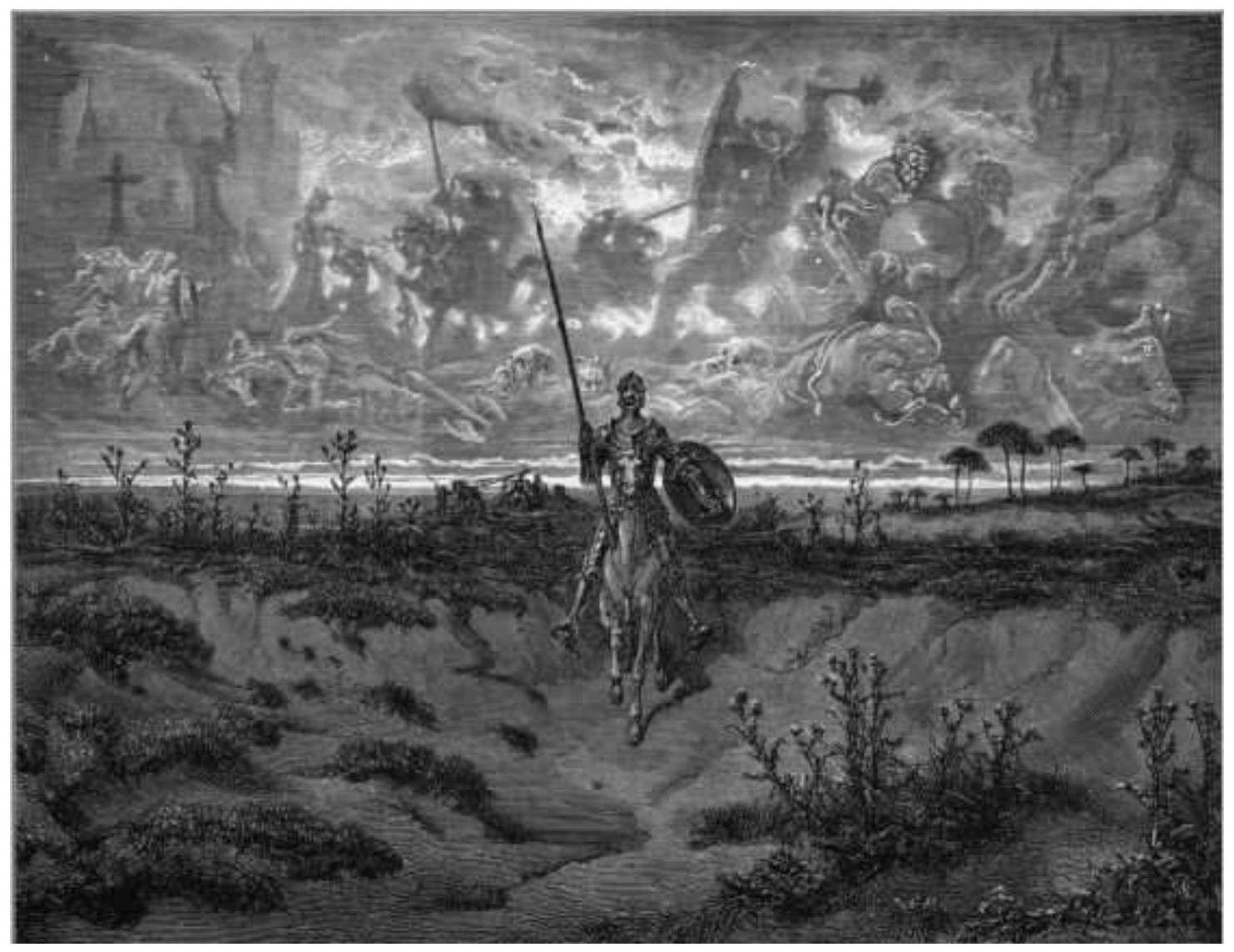

Grabado de Gustave Doré. Ilustración 2 Don Quijote sale por primera vez. (1833-1888)

\section{Claudia Patricia Mantilla Durán}

Doctora en Comunicación (T)

Universidad Nacional de La Plata - Argentina

Docente programa de Literatura Virtual

Universidad Autónoma de Bucaramanga

cmantilla9@unab.edu.co. 
Artículo recibido el 12 de abril del 2016

Aprobado el 02 de mayo del 2016

\section{A Santiago Sierra, por los libros}

Entre las muchas aventuras que vivió Don Quijote de La Mancha junto a su escudero Sancho, hay una en la que vencen al caballero de los espejos y que concluye con un curioso razonamiento sobre la locura. La locura, el idealismo, y la rebeldía quizá sean los grandes ejes temáticos en la obra de Don Miguel de Cervantes Saavedra. No en vano, Orlando Serrano Giraldo, experto en El Quijote, anota que estos temas suele encontrárselos no sólo en la obra cervantina sino en la vida, y añade: "El Quijote es antes que todo una proclama de libertad, una convocatoria al humanismo y un canto a la vida. También fue una gran terapia porque, gracias al Quijote Don Miguel de Cervantes pudo exorcizar todos los demonios que la vida le regaló”.

Pues bien, pasada la contienda con el caballero de los espejos, Don Quijote encuentra a un discreto caballero, vestido con un gabán de paño fino verde, se trata de Don Diego de Miranda, con quien sostiene una charla de carácter filosófico sobre el amor que se ha de profesar a los hijos. "Los hijos, señor, son pedazos de las entrañas de sus padres, y así, se han de querer, o buenos, o malos que sean, como se quieren las almas que nos dan vida" (De Cervantes, 2015), afirma el de la triste figura.

El encuentro acontece en el capítulo XVI de la segunda parte del inmortal libro, y es la perfecta ocasión para reflexionar sobre la poesía, puesto que a Don Diego le preocupa que su hijo se quiera dedicar al arte de las letras clásicas, y no a las leyes o a la teología. A lo que Don Quijote sabiamente replica: "que vuesa merced deje caminar a su hijo por donde su estrella le llama". (De Cervantes, 2015)

Mucho se ha dicho de los dos caballeros que allí toparon (Don Quijote y Don Diego), Randolph D. Pope afirma que en la conversación que sostienen hay un conflicto soterrado puesto que, "es frecuente en las historias de héroes y santos enfrentarlos a otras posibilidades de vida" (Redondo, s.a.), y en este caso, Don Quijote podría tentarse de una vida, aparentemente más segura y menos esforzada, como la de Don Diego.

También se les ha querido comparar en sus formas de montar:

Don Quijote, el que tiene la vista vuelta hacia el pasado y la mítica Edad de Oro de la caballería andante, no se desplaza rápidamente, viste la armadura anticuada y remendada de sus bisabuelos, cabalga en un escuálido rocín y como los héroes de los libros de caballerías - empezando por el 
admirado Amadís de Gaula — no puede montar sino a la brida, o sea con estribos largos, que mantienen la pierna tendida y dan estabilidad al pesado jinete. Al contrario, Diego de Miranda - el que mira al presente y al futuro_, representa la otra manera de montar de los nobles españoles, es decir a la jineta, con estribos cortos. Este modo de cabalgar - de origen moro - mantiene la pierna medio doblada lo que permite sujetar mejor al caballo y da más ligereza y agilidad al jinete (De Cervantes, 2015)

A su vez se han considerado sus maneras de vestir y de hablar, la posición social que ocupan, como queriendo ver secretas alusiones -seguramente las habrá- pero, lo que resulta verdaderamente trascendental en este pasaje es la elocuente defensa que Don Quijote hace de la poesía.

(...) La poesía, señor hidalgo, a mi parecer, es como una doncella tierna y de poca edad, y en todo estremo hermosa, a quien tienen cuidado de enriquecer, pulir y adornar otras muchas doncellas, que son todas las otras ciencias, y ella se ha de servir de todas, y todas se han de autorizar con ella (De Cervantes, 2015)

Por eso, cuando escucho a alguien desdeñar la poesía, especialmente si es un lector, con expresiones del talante: "lo mío es la prosa, no la poesía", pienso que olvida las sabias palabras de don Quijote puesto que, la poesía se alimenta de todas las esferas humanas y, a su vez añade en ellas una atmósfera que las eleva. Prosigue don Quijote:

Esta tal doncella (la poesía) no quiere ser manoseada, ni traída por las calles, ni publicada por las esquinas de las plazas ni por los rincones de los palacios. Ella es hecha de una alquimia de tal virtud, que quien la sabe tratar la volverá en oro purísimo de inestimable precio; hala de tener - el que la tuviere- a raya, no dejándola correr en torpes sátiras ni en desalmados sonetos; no ha de ser vendible en ninguna manera, si ya no fuere en poemas heroicos, en lamentables tragedias, o en comedias alegres y artificiosas; no se ha de dejar tratar de los truhanes, ni del ignorante vulgo, incapaz de conocer ni estimar los tesoros que en ella se encierran. Y no penséis señor, que yo llamo aquí vulgo solamente a la gente plebeya y humilde (De Cervantes, 2015).

Que si el poeta nace o se hace, responde Don Quijote:

(...) según es opinión verdadera, el poeta nace: quieren decir que del vientre de su madre el poeta natural sale poeta; y con aquella inclinación que le dio el cielo, sin más estudio ni artificio, compone 
cosas, que hace verdadero al que dijo: «est Deus in nobis»-etc. También digo que el natural poeta que se ayudare del arte será mucho mejor y se aventajará al poeta que solo por saber el arte quisiere serlo; la razón es porque el arte no se aventaja a la naturaleza, sino perficiónala; así que mezcladas la naturaleza y el arte, y el arte con la naturaleza, sacarán un perfetísimo poeta (De Cervantes, 2015).

Esta diáfana disertación sobre el valor de la poesía sorprende a Don Diego de Miranda pues, en un inicio y ateniéndose a la apariencia de Don Quijote se inclina a pensar que éste ha perdido el juicio. Asombrado con la lucidez de sus palabras halla a un hombre capaz de discernir entre la poesía de romance y los meros romancistas, un desatinado que sabe que "la pluma es lengua del alma" y que "letras sin virtud son perlas en el muladar", uno tal que reconoce que aunque "la poesía sea menos útil que deleitable" es necesaria y no deshonra a quien bien la posee.

El del verde gabán ha suscitado numerosas interpretaciones sobre el pensamiento mítico que reside en Don Quijote y el significado de la novela en el universo cervantino, lo cierto es que ante los ojos de la imaginación de los lectores, Don Quijote de La Mancha es y será el soñador por excelencia, el caballero "seco de carnes y enjuto de rostro" que cree ver en un carro de banderas la oportunidad de una nueva aventura, y en los molinos de viento desaforados gigantes prestos a la batalla.

\section{Referencias}

De Cervantes, M. (2015) Don Quijote de la Mancha. Madrid: Real Academia Española. Barcelona: EspasaCírculo de Lectores.

Redondo, A. (s.a.) "Nuevas consideraciones sobre el personaje del caballero del verde gabán”. En: Actas II. Asociación Cervantistas. Centro virtual Cervantes. Disponible en: http://cvc.cervantes.es/literatura/cervantistas/congresos/cg_II/cg_II_45.pdf

\section{Notas}

(1). Citar este artículo como: Mantilla, C. (2016) "El caballero del verde gabán”. En: Revista La Tercera Orilla (16). Bucaramanga: Universidad Autónoma de Bucaramanga 